\title{
LITERATURA NA EDUCAÇÃO INFANTIL
}

\author{
LITERATURE IN CHILD EDUCATION \\ Claudia da Silva Valadão ${ }^{1}$ \\ Crist Wilian de Moura Barbosa da Silva ${ }^{2}$ \\ Eliane Paes dos Santos ${ }^{3}$ \\ Kenned Júnior Ferreira de Sousa ${ }^{4}$
}

\begin{abstract}
RESUMO: No contexto da educação infantil, a literatura se insere através da importância do aprendizado para a criança. A literatura está presente no ensino e aprendizado, desenvolvida pelos educadores. Este estudo qualifica-se em pesquisa bibliográfica. Neste contexto, seapresenta a questão para problematização: Qual a importância das estratégias de ensino na utilização da literatura na educação infantil? Este estudo possui o objetivo de discutir as estratégias de ensino para se empregar a literatura infantil no processo de ensinoaprendizagem. Os objetivos específicos definem-se da seguinte forma: contextualizar a educação infantil; refletir sobre a literatura infantil; e abordar as estratégias de ensino que se utilizam da literatura infantil como instrumento no processo de ensino-aprendizagem. Abordou-se os teóricos: Paivae Oliveira (2010); Dessen e Polônia (2007); Alves (2011); Simões (2013); Tortella et al (2016); Silva e Francischini (2012); Ferreira e Barreira (2010); e Campos et al (20II). As estratégias de ensino são importantes para a literatura infantil se concretizar como recurso didático no processo de ensino-aprendizagem, tornando-se agregadora à formação de um leitor e cidadão.
\end{abstract}

Palavras-chave: Educação Infantil. Literatura Infantil. Estratégias de Ensino na Educação Infantil. Processo de Ensino-aprendizagem.

ABSTRACT: In the context of early childhood education, literature is inserted through the importance of learning for the child. Literature is present in teaching and learning, developed by educators. This study qualifies in bibliographic research. In this context, the question is presented: What is the importance of teaching strategies in the use of literature in early childhood education? This study aims to discuss the teaching strategies to use

\footnotetext{
I Licenciada em Letras e aluna da Segunda Licenciatura em Pedagogia (Faculdade Delta), e-mail: claudiavaladaozi@hotmail.com.

${ }^{2}$ Licenciado em Geografia (UNIP) e aluno da Segunda Licenciatura em Pedagogia (Faculdade Delta), e-mail: cristwilian@hotmail.com.

3 Licenciada em Letras (Universidade Estadual de Goiás) e aluna da Segunda Licenciatura em Pedagogia (Faculdade Delta),e-mail: elianepaesı@gmail.com.

${ }^{4}$ Licenciado em Letras Português/Inglês e aluno da Segunda Licenciatura em Pedagogia (Faculdade Delta), email: kenned.junior@hotmail.com.
} 
children's literature in the teaching-learning process. The specific objectives are defined as follows: contextualize early childhood education; reflect on children's literature; and address the teaching strategies that use children's literature as an instrument in the teachinglearning process. Theorists were approached: Paiva and Oliveira (2010); Dessen and Poland (2007); Alves (2011); Simões (2013); Tortella et al (2016); Silva and Francischini (2012); Ferreira andBarrier (2010); and Campos et al (2011). Teaching strategies are important for children's literature to become a didactic resource in the teaching-learning process, becoming aggregating to the formation of a reader and citizen.

Keywords: Child education. Children's literature. Teaching Strategies in Early Childhood Education. Teaching-learning process.

\section{INTRODUÇÃO}

O aprendizado é um componente de todo o ciclo de vida do homem, base para a sua sobrevivência e desenvolvimento. Ao nascer, a criança se insere numa sociedade dinâmica envolvida por constantes mudanças, que valoriza o conhecimento. $\mathrm{Na}$ fase de desenvolvimento, descobertas são realizadas e conhecimentos são apropriados. A apropriação do conhecimento decorre das relações sociais, num processo ao qual utiliza-se a comunicação e a linguagem.

No contexto da educação infantil, a literatura se insere através da importância do aprendizado para a criança. A literatura está presente no ensino e aprendizado, desenvolvida pelos educadores. Desta maneira, a literatura se constitui um instrumento de aprendizado em todo processo de formação da criança na escola, evidenciando a sua importância por meio dasbases de conhecimento proporcionada. A literatura está alinhada ao desenvolvimento da escritae da imaginação da criança, contribuindo para o desenvolvimento de habilidades e competências no processo de ensino-aprendizagem.

Apesar do amplo conjunto de títulos existentes na literatura infantil, o professor se depara com dificuldades para se trabalhar com estas obras em alinhamento aos objetivos do processo de ensino-aprendizagem, reconhecendo as especificidades existentes entre os alunos de uma sala de aula de educação infantil. Neste contexto, se apresenta a questão para problematização: Qual a importância das estratégias de ensino na utilização da literatura na educação infantil?

Neste contexto, este estudo possui o objetivo de discutir as estratégias de ensino para 
se empregar a literatura infantil no processo de ensino-aprendizagem. Os objetivos específicos definem-se da seguinte forma: contextualizar a educação infantil; refletir sobre a literatura infantil; e abordar as estratégias de ensino que se utilizam da literatura infantil como instrumento no processo de ensino-aprendizagem.

Este estudo qualifica-se como uma pesquisa bibliográfica, utilizando-se de um aprofundamento em estudos de renomados especialistas na área do tema abordado neste estudo. $O$ primeiro capítulo discorre sobre a contextualização da educação infantil na educação básicabrasileira. O segundo capítulo aborda uma reflexão sobre a literatura infantil. O terceiro capítuloaborda sobre as estratégias de ensino na educação infantil, com enfoque na utilização na utilização da literatura infantil como instrumento de apoio ao desenvolvimento do processo deensino-aprendizagem.

\section{METODOLOGIA}

Neste estudo foi utilizada a pesquisa bibliográfica. Realizou-se levantamento em fontesbibliográficas para promover a discussão objeto deste estudo. As fontes bibliográficas foram: artigos científicos e monografias. No desenvolvimento textual, realizou-se uma dialogo entre diversos autores de estudos da abordagem da educação infantil e da literatura infantil.

Destarte, em relação à pesquisa bibliográfica, foram interpretados teóricos que abordamo tema estudado em Paiva e Oliveira (2010); Dessen e Polônia (2007); Alves (2011); Simões (2013); Tortella et al (2016); Silva e Francischini (2012); Ferreira e Barreira (2010); e Camposet al (2011).

\section{DISCUSSÃO TEÓRICA Educação Infantil}

A educação infantil é componente da educação básica, onde se trabalha o desenvolvimento inicial escolar das crianças, que se enquadram na faixa etária que antecede aos 7 anos de idade. Desta maneira, a educação infantil atende aluno de o a 6 anos completadosem 3 I de março do ano letivo, enquanto as séries iniciais do ensino fundamental atendem crianças dos 6 aos II anos. 
As primeiras ideias da concepção de creche no país se desenvolveram a partir da participação do imperador Dom Pedro II e da Imperatriz na vigésima sessão pública da Sociedade das Creches em Paris, definindo uma versão brasileira das creches com fundamentação em uma sociedade beneficente que desejam concorrer e fundar uma instituiçãopara crianças pobres de menos de dois anos, de mães que trabalham fora dos seus domicílios epossuem uma boa conduta. De acordo com Silva e Francischini (2012), as creches surgem pormeio de uma divisão de classes, ao se propor atender somente as crianças pobres.

Campos et al (20II) observam uma evolução na educação infantil nas últimas décadas, em decorrência da ampliação do acesso destas crianças às creches e pré-escolas. Os referidos autores compreendem que essa condição foi influenciada pelos seguintes processos sociais: urbanização, crescimento econômico, lutas sociais, mudança do papel da mulher na sociedadee resultado de políticas públicas educacionais.

Paschoal e Machado (2009) contextualizam que a educação da criança esteve sob a responsabilidade exclusiva da família durante séculos, embasada na condição de aprender as normas e regras culturais na convivência com os adultos e as outras crianças. Ferreira e Barreira(2010) salientam que a família se constitui o primeiro ambiente de socialização do indivíduo euma das fundamentais instituições mediadoras de padrões e modelos culturais. A instituição escolar é um componente que se agregou à vida das crianças na contemporaneidade.

$\mathrm{Na}$ contemporaneidade, o desenvolvimento das instituições escolares proporcionou umaoportunidade de as crianças desenvolverem as relações sociais e constituir bases para o seu desenvolvimento em sociedade. Paschoal e Machado (2009) ressaltam que este ambiente de socialização possibilita que as crianças aprendam sobre a sua cultura por meio das interações sociais.

Alves (20II) ressalta que o surgimento de novas concepções de criança indica que a educação infantil deve ser promotora de uma aprendizagem, fundamentada na integralidade e indivisibilidade das dimensões do seu desenvolvimento. A referida autora visualiza uma intensarevisão de concepção da educação infantil em espaços coletivos, mudando do enfoque assistencial para o educacional, constituindo um processo que demanda a discussão sobre a nãodissociação entre o educar e o cuidar e o estimula o desenvolvimento de questões 
relativas ao trabalho pedagógico nas creches e pré-escolas.

Apesar desta condição, a escola não substituiu a família. Dessen e Polônia (2007) evidenciam que a família ainda proporciona a formação inicial de repertórios comportamentais, de ações e resoluções de problemas. Ferreira e Barreira (2010) compreendem que a escola e a família são os dois principais ambientes de desenvolvimento do indivíduo e, consequentemente,se apresenta como fundamental uma maior ligação entre ambas. As referidas autoras observamque a valorização da relação entre família e escola deve ser iniciada no projeto pedagógico, como reconhecimento e trabalho com as práticas educativas familiares como recurso de aprendizagem dos alunos.

Alves (20II) aborda que o desenvolvimento e a socialização não sintetizam o papel da educação. A referida autora complementa que a educação infantil é uma etapa da educação básica e se integra ao sistema de ensino e, consequentemente, deve promover o acesso aos conhecimentos produzidos pelo homem em diversos tempos, espaços e culturas, embasandosena contextualização, na criticidade e na adequação às faixas etárias, contribuindo para ampliação do universo cultural da criança, da compreensão da realidade e a interação com o mundo. Neste contexto de ampliação da educação infantil do país ao final do século XX, esta etapa educacional deve continuar promovendo o desenvolvimento e a socialização da criação em articulação com a promoção do conhecimento, apenas ampliando o seu alcance junto a população de crianças.

Correa (2011a) aborda que a aprovação da emenda complementar 59 (BRASIL, 2009) foi fundamental para promoção da ampliação da educação infantil, pois determinou a obrigatoriedade da matrícula de todas as crianças a partir dos quatro anos de idade. A referida autora contempla que esta condição evidenciou novos desafios para o Estado garantir as vagasnecessárias ao atendimento de todas as crianças de quatro e cinco anos, acompanhada da qualidade da qualidade de ensino. As políticas públicas educacionais são fundamentais para o Estado trabalhar estas questões desafiantes ao desenvolvimento de uma educação infantil promovedora de um ensino de qualidade.

Silva e Francischini (2012) salientam que a atuação ativa do Estado em relação às políticas públicas voltadas para a criança se iniciou a partir do período da República Velha (I889 a 1930). As referidas autoras evidenciam o desenvolvimento de instituições de ensino 
com objetivos diversificados neste período: Jardim da Infância, I897, visava educar as criançascom idade entre 4 e 7 anos, com a utilização de jogos, cantos, danças, marchas e pinturas; e implementação de creches para filhos de operários com até dois anos, com enfoque em práticasvoltadas para crianças de zero a seis anos era de caráter médico.

A concepção sobre a educação infantil passou por mudanças, acompanhando a modernização da sociedade em decorrência das tecnologias e, consequentemente, das mudanças culturais. Silva e Francischini (2012) relatam que a educação infantil passou a ocuparmaiores espaços nas políticas públicas educacionais a partir do final do século XX, evidenciando a falta de cuidado com a infância brasileira. As referidas autoras enfatizam a importância de se refletir sobre a educação infantil, pois o papel assistencialista marca as instituições de ensino públicas e o papel educacional se mantém nas instituições de ensino privadas.

Esta reflexão é importante no desenvolvimento das políticas públicas da educação infantil, inclusive contemplando os seus três componentes. Kramer, Nunes e Corsino (20II) ressaltam que o desenvolvimento de políticas públicas de redistribuição e reconhecimento das creches se constitui fundamental, quando se apresenta uma perspectiva do atendimento aos direitos humanos e a construção de mecanismo institucionais que possibilitem o enfrentamentoaos fatores socioeconômicos e culturais perpetuadores da injustiça social no país. Portanto, as políticas públicas da educação infantil devem considera o aspecto da injustiça social que envolve a sociedade brasileira em todo o seu processo histórico.

As políticas públicas educacionais se embasam em três fatores: normas, financiamentoe fiscalização. Correa (20Ira) analisa estes três fatores nas políticas públicas da educação infantil: as normas, estas se caracterizam por aspectos ainda não consolidados, apesar de estabelecidos pela legislação; o financiamento, apesar da educação infantil ser inclusa na composição dos recursos do Fundeb (Fundo de Manutenção e Desenvolvimento da Educação Básica), apresenta-se inexistente ou frágil para suprimento das demandas específicas dotrabalho educacional que envolve as crianças na faixa de o a 6 anos; e fiscalização, não se apresenta em funcionamento efetivo, pois os sistemas municipais mal conseguem acompanhar as instituições de ensino de suas redes e, consequentemente, negligenciando a fiscalização dasescolas públicas de educação infantil. Em decorrência da 
carência de recursos para estrutura física e contratação de pessoal para supervisão. A referida autora conclui que os três fatores desustentação das políticas públicas de educação infantil encontram-se em desequilíbrio, principalmente pela carência de recursos para financiamento de uma estrutura que possibilite aconcretização do direito à educação infantil, apesar da existência de terminação na legislação.

Campos et al (20II) contemplam que as mudanças legais impulsionaram a implementação do ensino fundamental de 9 anos no país, com a inclusão do último ano da pré-escola, na condição de estratégia de apressar a universalização o atendimento educacional às crianças de 6 anos. Os referidos autores acrescentam que estratégia de política educacional implicou na redução da pré-escola de três para dois anos, correspondente à faixa etária de 4 e 5 anos, e ampliação da fase inicial do ensino fundamental de 4 para 5 anos.

Essas reformas educacionais proporcionam mudanças nos trabalhos administrativos dasinstituições de ensino e nas práticas pedagógicas. Ao analisar um sistema educacional municipal, Correa (20Irb) visualizou que os professores e diretores da pré-escola não foram instruídos das mudanças no ensino fundamental no ano de sua implementação, apesar de influenciar nos seus trabalhos. A referida autora complementa que as orientações da secretaria educacional se restringiram o seu enfoque na organização de matrículas, negligenciando a abordagem sobre as mudanças no desenvolvimento do trabalho pedagógico nas turmas de 3, 4e 5 anos de idade que passaram a compor as pré-escolas.

A ausência de preparação das práticas docentes para as mudanças pedagógicas não foi o único fator que foi negligenciado pelo Estado na implementação destas reformas educacionaisna educação infantil e no ensino fundamental. Campos et al (20II) destacam que estas reformas educacionais forma implementadas sem a garantia de condições de infraestrutura, formação docente, redução de número de alunos por turma, adaptação de currículos e materiais didáticos, entre outras, que possibilitassem uma transição menos desarticulada para o novo formato. Os

referidos autores complementam que estes percalços se desenvolvem conjuntamente aos esforços das prefeituras em atender à demanda por vagas na educação infantil, em promover aintegração do atendimento que era de responsabilidade estadual e constituir a adequação de instituições conveniadas aos padrões adotados pelo setor de educação. 
Silva e Francischini (2012) ressaltam que a educação infantil é abordada por diversos documentos e legislações constituídas ao final do século XX, inclusive a Constituição Federal de 1988. Essa situação demonstra que a educação infantil se encontra inserida em um amplo debate entre especialistas, sociedade e Estado. Apesar disso, demanda-se refletir sobre a sua funcionalidade da educação infantil e seus componentes estruturais para se concretizar como um direito universal das crianças no país. Neste contexto, se desenvolve a literatura infantil pormeio de estratégias de ensino específicas, que se aplicam ao processo de ensinoaprendizagemda educação infantil.

\section{Literatura Infantil}

Os livros infantis encontram o seu desenvolvimento nos espaços escolares, de forma espontânea ou obrigatória em uma atividade em sala de aula. Lajolo (2008) enfatiza a importância da literatura literária, caracterizada como linguagem e como instituição, que envolvem os diferentes imaginários, as diferentes sensibilidades, valores e comportamentos quesão expressos do cotidiano da sociedade. A referida autora compreende que esta condição

fundamenta a importância da literatura no currículo escolar, pois o cidadão demanda a posse dalinguagem literária em sua alfabetização e uso da língua e, consequentemente, o exercício pleno de sua cidadania. Neste contexto, a literatura infantil é componente inicial da linguagem literária.

Paiva e Oliveira (2010) ressaltam que a existência de críticas de especialistas em relação à concepção de literatura infantil como um conjunto de publicações de conteúdo recreativo e/oudidático para o público infantil. Frantz (200I) define a literatura infantil pelos seus aspectos deludismo, fantasia, questionamento e capacidade de prover respostas para inúmeras indagações do mundo infantil. Considerada esta concepção, a referida autora contempla que a literatura infantil se constitui um instrumento de enriquecimento da capacidade de percepção das cosias pelas crianças.

Bettelheim (2007) conceitua a literatura infantil como aquela detentora do objetivo de desenvolver a mente e a personalidade da criança, e não se restringindo ao divertimento e à informação, transmitindo as experiências da vida. Peres, Marinheiro e Moura (2012) ressaltam que a literatura infantil se originou nas fábulas, principalmente as orientais, 
transmitidas oralmente entre gerações, desde séculos antes de Cristo. Os referidos autores visualizam que a literatura infantil não possui uma origem infantil, e passaram por dificuldades para se introduzirem ao mundo literário, pois as crianças eram marginalizadas pelas ausências de respeito e de consideração como parte da população humana.

Simões (2013), aborda que as concepções de infância vigentes na literatura infantil contemporânea são fundamentadas na visão dos adultos, pois os autores não podem se desvincular de sua condição de adulto mesmo que tente assumir a perspectiva de uma criança leitora da obra. A referida autora observa a importância de se considerar a perspectiva do adultoem olhar infância detém diferenças e distâncias em relação à perspectiva da criança, e se apresenta passível de idealizações.

$\mathrm{Na}$ literatura infantil, os clássicos são compostos pelas seguintes obras: Cinderela, Branca de Neve, Bela Adormecida, Chapeuzinho Vermelho, e entre outras narrativas oriundasdo continente europeu. Peres, Marinheiro e Moura (2012) enfatizam que os clássicos da literatura infantil possuem uma forte presença na sociedade, pois as crianças ainda se encantamcom as suas histórias. Os referidos autores observam que os clássicos ainda marcam o imaginário infantil, apresentando narrativas caracterizadas pela presença de personagens que seenquadram em um padrão simbolizado como ideal.

Paiva e Oliveira (2010), destacam a utilização das fábulas como recursos didáticos nas séries iniciais do ensino fundamental, que consistem em narrativas curtas, baseadas em personagens de animais, plantas ou objetos animados possuidores de aspectos humanos, e apresentam um ensinamento ao seu término. As referidas autoras caracterizam as fábulas comodetentoras de um método pedagógico que não demanda reflexão ou questionamento.

Simões (2013), caracteriza o surgimento das fábulas como um período em que a criança era considerada um indivíduo pronto para recepção da educação como uma dádiva e amar a sua pátria. A referida autora complementa que a literatura infantil deste período se apresentava como instrumento pedagógico embasado na exemplaridade e pela doutrinação. A gerações contemporâneas de crianças não podem ser visualizadas igualmente às demais gerações de crianças, em decorrência das mudanças culturais provenientes dos avanços tecnológicos e da globalização.

A ampliação da circulação de obras da literatura infantil vincula-se ao seu emprego 
nasescolas. Neste contexto, Oliveira (2015) destaca a importância dos manuais e programas de ensino se tornaram parâmetros para os autores especializados na literatura infantil desenvolverem as suas obras. O referido autor apresenta detalhamento profundo dos parâmetros das obras infantis a serem empregadas no processo de ensino-aprendizagem da educação infantil:

Estes aspectos das obras de literatura infantil apresentam-se diversificados mediante a complexidade que envolve o processo de formação escolar na educação infantil. Apesar desta influência dos manuais e programas de ensino, Simões (2013) observa que as obras da literaturainfantil contemporânea se consolidam como uma produção literária que não se restringe a meracondição de recurso pedagógico, mas desenvolve as principais funções de lúdica, catártica e libertadora, além do cognitivo e do pragmático, já que possui o objetivo de preparar o indivíduopara uma realidade contemplada pelas diversidades.

De acordo com Corso e Corso (2006), a infância passou por mudanças que influenciaram no processo de formação das crianças na contemporaneidade, pois estas preferemhistórias que não detenham uma intenção embutida de educa-las. Reis, Torres e Costa (2016) observam que a literatura possui a missão de estimular nas crianças a curiosidade, a criatividadee a capacidade de questionamentos e reflexões, se desenvolvendo além dos limites didáticos.

Considerada as devidas expectativas e compreensões sobre a literatura infantil, esta se insere no processo de ensino-aprendizagem da educação infantil. O planejamento possibilita que a literatura infantil se alinhe às estratégias de ensino, priorizando os objetivos do processode ensino-aprendizagem das turmas da educação infantil.

\section{Estratégias de Ensino: a utilização da Literatura Infantil no Processo de Ensino- aprendizagem}

Os professores de educação infantil implementam e aprimoram as estratégias de ensinopara alinhar as obras de literatura infantil ao processo de ensino-aprendizagem, para estimularo desenvolvimento de habilidades e competências nos alunos. Reis, Torres e Costa (2016) observam que estas estratégias de ensino devem considerar o trabalho com crianças que adoramopinar, que se alinham ao ideal democrático e não aceitam nada que não tenha 
compreendido ou elaborado. Portanto, estes alunos da educação infantil demandam espaços de fala e discussãoem sala de aula, durante o desenvolvimento do processo de ensinoaprendizagem.

Paiva e Oliveira (2010) destacam a importância da técnica de desenvolvimento e da linguagem para aplicação da literatura infantil no processo de ensino-aprendizagem. As referidas autoras complementam que a técnica de desenvolvimento consiste em uma representação clara, compreensível e sem infantilidade, enquanto que a linguagem é exigida pelo leitor infantil em uma concepção simples, bem cuidada e agradável.

Tortella et al (2016) abordam a utilização da literatura infantil em articulação com as brincadeiras e as ferramentas tecnológicas, com enfoque em desenvolver a curiosidade e levantar as devidas explicações. Os referidos autores ressaltam que esta estratégia de ensino transforma a literatura infantil em um recurso pedagógico movido a partir da curiosidade dos alunos da educação infantil, promovendo histórias que possibilitam as crianças organizarem e construírem as suas próprias memórias.

Alves e Rodrigues (2016) abordam sobre a estratégia de ensino que aborda o texto literário infantil mediante uma perspectiva de diálogo entre o texto e leitor, promovendo a valorização do sujeito leitor, suas experiências, percepções do mundo e das obras, e ampliaçãodos seus horizontes de expectativas. Os referidos autores complementam que esta estratégia deensino se desenvolve sobre um paradigma interacionista, utilizando-se da leitura compartilhadapara estimular o aprendizado com o outro e a contribuição com ele. Neste contexto, o professorse posiciona como mediador, questionador e aprendiz, fugindo de uma posição tradicional parauma dinamicidade no processo de ensino-aprendizagem.

Cardoso (2019) relata sobre a estratégia de ensino do cantinho da leitura na educação infantil, que envolve um cantinho da sala de aula que o professor promove uma pequena biblioteca, aonde o aluno retira um livro emprestado para leitura. A referida autora contempla que esta estratégia de ensino possibilita o desenvolvimento de um momento de tranquilidade edescontração entre os alunos e o professor, e potencializa a leitura se tornar um hábito gostosoe rotineiro.

Tierno (2010) aborda sobre a estratégia de ensino que se utiliza de fantoches e teatros alinhados às histórias abordadas na literatura infantil, que se constituem chamativos e 
atraem aatenção das crianças em sala de aula. O referido autor ressalta que esta estratégia de ensino possibilita que as crianças expressem sentimentos, brinquem livremente e abandonem a timidez, desenvolvendo relações sociais de amizade e se expressando com mais facilidade, quando estão mediantes aos fantoches.

Desta maneira, as estratégias de ensino se articulam ao recurso didático da literatura infantil, observando a linguagem e o desenvolvimento das crianças na sala de aula. Os professores planejam estas estratégias de ensino com a literatura infantil, e mediam o processode ensino-aprendizagem em cumprimento aos seus objetivos em relação à formação cidadã dosalunos da educação infantil.

\section{CONSIDERAÇÕES FINAIS}

A educação infantil é um componente consolidado na segunda metade do século XIX,envolvendo uma relação com a desigualdade social, pois as primeiras instituições visavamatender as mães pobres que trabalhavam fora de seu domicílio. A partir de sua implementação,a educação infantil passou por transformações em seu desenvolvimento, para se alinhar aosinteresses do Estado e da sociedade de sua época. As políticas públicas são instrumentosfundamentais para a promoção do desenvolvimento da educação infantil. As mudanças recentesno ensino fundamental influenciaram a estruturação da educação infantil, evidenciando osproblemas de ambas etapas da educação básica brasileira, que envolve os componentes de estrutura, financiamento e fiscalização. Portanto, o desenvolvimento da educação infantil deveser pensado em articulação com a estrutura do ensino fundamental, por meio de diálogos entreos envolvidos em ambos os segmentos da educação básica. Além disso, as políticas públicas daeducação infantil devem ser pensadas em uma concepção de longo prazo, sem fragmentações.

Neste contexto da educação infantil, se insere a literatura infantil em seu processo de ensino-aprendizagem. A literatura infantil contribui para o desenvolvimento da imaginação eda personalidade da criança. Além das obras clássicas, foi desenvolvido um amplo conjunto deobras infantis na contemporaneidade, que abordam diversos temas do contexto das crianças. Desta maneira, a literatura infantil se torna um recurso didático no processo de ensino-aprendizagem da educação infantil. Os clássicos se caracterizam 
pela abordagem de uma visãoadulta em relação à infância. As obras contemporâneas mantêm esta posição em uma concepçãomodificada, ao abrir espaços para as crianças se expressarem e desenvolverem a sua identidade. As estratégias de ensino são importantes para alinhar os recursos didáticos da literatura infantil aos objetivos do processo de ensino-aprendizagem, possibilitando o desenvolvimentode uma formação cidadã desde a educação infantil. A seleção de estratégias de ensino segueaos objetivos do processo de ensino-aprendizagem, considerando o tema abordado. O professor planeja e media o desenvolvimento das estratégias de ensino. Entre as estratégias de ensino queenvolvem a literatura infantil podem ser citadas: a literatura infantil articulada com brincadeirase ferramentas tecnológicas; cantinho de leitura; teatros e fantoches; e o texto literário infantil mediante uma perspectiva de diálogo entre o texto e leitor.

Desta maneira, conclui-se que as estratégias de ensino são importantes para a literaturainfantil se concretizar como recurso didático no processo de ensino-aprendizagem, tornando-seagregadora à formação de um leitor e cidadão. A abordagem do texto literário se inicia na educação infantil para fomentar o desenvolvimento das crianças em sua formação educacional e cidadã. As políticas públicas são base para o desenvolvimento de uma educação infantil, que se utiliza de estratégias de ensino que fomentam o desenvolvimento de habilidades e competências nas crianças.

Considerada, a abordagem sugere-se o desenvolvimento de um estudo para discutir o desafio de articulação das tecnologias com a literatura infantil. O desenvolvimento desta sugestão de estudo se justifica pelo potencial de inserção da tecnologia no processo de ensinoaprendizagem da educação infantil.

\section{REFERÊNCIAS}

ALVES, Bruna Molisani Ferreira. Infâncias e educação infantil: aspectos históricos, legais e pedagógicos. Revista Aleph, n. 16, 20Ir. Disponível em: 〈http://www.revista-leph.uff.br/index.php/REVISTALEPH/article/viewFile/272/204>. Acesso em io de dezembro de 2019.

ALVES, José Hélder Pinheiro; RODRIGUES, Etiene Mendes. De São Saruê à Casa da madrinha: literatura de cordel e literatura infantil no espaço escolar. Revista Cerrados, v. 25, n. 42, p. 163-180, 2016. Disponível em: <http://periodicos.unb.br/index.php/cerrados/article/ download/25331/22317>. Acesso em io de dezembro de 2019. 
BETTELHEIM, Bruno. A psicanálise dos contos de fadas. 22 ed. Paz e terra, 2007.

BRASIL. Emenda Constitucional no 59, de in de novembro de 2009. 2009. Disponível em:〈http://www.planalto.gov.br/ccivil_03/constituicao/Emendas/Emc/emc59.htm〉. Acesso em ro de dezembro de 2019.

CAMPOS, Maria Malta et al. A qualidade da educação infantil: um estudo em seis capitais brasileiras. Cadernos de pesquisa, v. 4I, n. I42, p. 20-54, 20Ir. Disponível em:

〈http://www.scielo.br/scielo.php?pid=SoI0o-I5742011000100003\&script=sci_arttext-

$\& \ln g=e s>$. Acesso em ro de dezembro de 2019.

CARDOSO, Ieda Vaz Troncha. Literatura infantil e linguagem social no desenvolvimentoda criança no contexto da educação infantil. 2019. Monografia (Graduação em Segunda Licenciatura em Pedagogia), Instituto Federal Goiano, Campus

Ipameri, 2019.

CORREA, Bianca Cristina. Educação infantil e ensino fundamental: desafios e desencontros na implantação de uma nova política. Educação e Pesquisa, v. 37, n. I, p. I05-I20, 2011.

Disponível em: 〈https://www.redalyc.org/pdf/298/29819095007.pdf〉. Acesso em io de dezembro de 2019.

CORREA, Bianca Cristina. Políticas de educação infantil no Brasil: ensaio sobre os desafios para a concretização de um direito. Jornal de políticas educacionais, v. 5, n. 9, 2011.

Disponível em: 〈https://revistas.ufpr.br/jpe/article/view/25172〉. Acesso em ro de dezembro de 2019 .

CORSO, D. L; CORSO, M. Fadas no divã: psicanálise nas histórias infantis. Porto Alegre: Artmed; 2006.

DESSEN, Maria Auxiliadora; DA COSTA POLONIA, Ana. A família e a escola como contextos de desenvolvimento humano. Paidéia, v. 17, n. 36, p. 21-32, 2007. Disponível em: < http://www.scielo.br/pdf/paideia/vi7n36/vizn36a03>. Acesso em io de dezembro de 2019.

FRANTZ, Maria Helena Zancan. $O$ ensino da literatura nas séries iniciais. $-3^{\underline{a}}$ Ed. Ijuí, Ed. UNIJUI, 200I.

FERREIRA, Susie Helena Araújo; BARRERA, Sylvia Domingos. Ambiente familiar e aprendizagem escolar em alunos da educação infantil. Psico, v. 4I, n. 4, p. 12, 2010.

Disponível em: $\langle$ https://dialnet.unirioja.es/servlet/articulo?codigo=5161409〉. Acesso em rode dezembro de 2019.

KRAMER, Sonia; NUNES, Maria Fernanda; CORSINO, Patrícia. Infância e crianças de 6 anos: desafios das transições na educação infantil e no ensino fundamental. Educaçao e 
Pesquisa: Revista da Faculdade de Educação da Universidade de São Paulo, v. 37, n. I, p. 69-86, 20II. Disponível em: 〈http://www.scielo.br/pdf/ep/v37ni/v37niao5〉. Acesso emio de dezembro de 2019 .

LAJOLO, Marisa. Do mundo da leitura para a leitura do mundo. $6^{\underline{a}}$ ed. $13^{\underline{a}}$ impressão. São Paulo: Editora Ática, 2008.

OLIVEIRA, Fernando Rodrigues. Compreender o passado para repensar o presente: a literatura infantil na história da formação de professores. Nuances: estudos sobre Educação, v. 26, n. 3, p. 283-302, 2015. Disponível em: 〈http://revista.fct.unesp.br/index.php/Nuances/ article/view/3703>. Acesso em io de dezembro de 2019.

PAIVA, Sílvia Cristina Fernandes; OLIVEIRA, Ana Arlinda. A literatura infantil no processode formação do leitor. Cadernos da Pedagogia, v. 4, n. 7, 2010. Disponível em: 〈http://www.cadernosdapedagogia.ufscar.br/index.php/cp/article/viewFile/175/ror〉. Acessoem io de dezembro de 2019.

PASCHOAL, Jaqueline Delgado; MACHADO, Maria Cristina Gomes. A história da educação infantil no Brasil: avanços, retrocessos e desafios dessa modalidade educacional. Revista Histedbr on-line, v. 9, n. 33, p. 78-95, 2009. Disponível em:< https://periodicos.sbu.unicamp.br/ojs/index.php/histedbr/article/view/8639555>. Acesso emio de dezembro de 2019.

PERES, Fabiana Costa; MARINHEIRO, Edwylson de Lima; MOURA, Simone Moreira de. A literatura infantil na formação da identidade da criança. Revista Eletrônica Pró-Docência, UEL, n. I. Disponível em: <http://www.academia.edu/download/32261445/ SIMONE_MOURA-FABIANA-EDWYLSON_-_pedagogia.pdf $>$. Acesso em io de dezembro de 2019 .

REIS, Mariana Pereira dos; TORRES, Eneida Pena Pereira; COSTA, Beethoven Hortencio Rodrigues da. Infância, escola e literatura infantil: livro para criança não precisa ser educativo. Revista Psicopedagogia, v. 33, n. IOI, p. I84-195, 2016. Disponível em: http://pepsic.bvsalud.org/scielo.php?script=sci_arttext\&pid=So103-84862016000200008 $>$. Acesso em ro de dezembro de 2019 .

SILVA, Carmem Virgínia Moraes da; FRANCISCHINI, Rosângela. O surgimento da educação infantil na história das políticas públicas para a criança no Brasil. Práxis Educacional, Vitória da Conquista v. 8, n. 12 p. 257-276 jan./jun. 2012. Disponível em: 〈http://www.udc.edu.br/libwww/udc/uploads/uploadsMateriais/o7o82018080509Hist\%C 3\% B3rico\%2oedu\%20infantil\%20_\%2opostar\%2opara\%2oturma.pdf $>$. Acesso em io de dezembro de 2019.

SIMÕES, Lucila Bonina Teixeira. Literatura infantil: entre a infância, a pedagogia e a arte. Cadernos de Letras da UFF, v. 23, n. 46, 2013. Disponível em: 〈http://www. cadernosdeletras.uff.br/index.php/cadernosdeletras/article/view/455>. Acesso em io de 
dezembro de 2019.

TIERNO, G. Pegadas reflexivas acerca da arte de contar histórias: A teia do invisível. In Tierno, G. (org.) A arte de contar histórias: abordagens poética, literária e performática. $\mathrm{I}^{\mathrm{a}}$. ed. São Paulo: Ícone, zoro.

TORTELLA, Jussara Cristina Barboza et al. Histórias e memórias na educação infantil: Um elo entre literatura infantil, PNBE e prática pedagógica. Nuances: estudos sobre Educação, v. 27, n. 2, p. 134-151, 2016. Disponível em: 〈http://revista.fct.unesp.br/index.php/Nuances/article/view/3715>. Acesso em io de dezembro de 2019. 